\title{
Pengaruh Debt To Total Asset Ratio (DAR) dan Debt To Equity Ratio (DER) Terhadap Net Profit Margin (NPM) Serta dampaknya terhadap Harga Saham pada Perusahaan Elektronik di Bursa Efek Tokyo tahun 2007-2016
}

\author{
Destian Andhani ${ }^{1}$ \\ 1) dosen Universitas Pamulang, email : destianandhani08@gmail.com
}

\section{ARTICLES \\ INFORMATION}

ABSTRACT

\section{JURNAL SEKURITAS (Saham, Ekonomi, \\ Keuangan dan Investasi) \\ Vol.3, No.1, September 2019 \\ Halaman : $45-64$ \\ () LPPM \& Prodi Manajemen \\ UNVERSITAS PAMULANG \\ ISSN (online) : 2581-2777 ISSN (print) : 2581-2696}

\section{Keyword:}

$D A R, D E R, N P M$, Harga

Saham

\section{JEL Classification :}

C33, G21, G24, N15, N25

\section{Contact Author: \\ PRODI MANAJEMEN UNPAM \\ JL.Surya Kencana No.1Pamulang \\ Tangerang Selatan-Banten \\ Telp. (021) 7412586, Fax (021) 7412491 Email : \\ jumalfinance.unpam@gmail.com}

sekuritas@unpam.ac.id

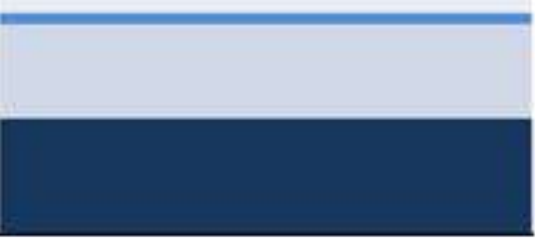

Penelitian ini bertujuan untuk mengetahui pengaruh Debt To Total Asset Ratio (DAR) Dan Debt To Equity Ratio (DER) Terhadap Net Profit Margin (NPM) Serta Dampaknya Terhadap Harga Saham pada perusahaan Elektronik Di Bursa Efek Tokyo Tahun 2007-2016.

Metode analisis yang digunakan adalah analisis deksriptif assosiatif. Analisis data meliputi uji kelayakan data, analisis regresi, serta pengujian hipotesis secara parsial dan simultan.

Hasil penelitian ini menunjukan bahwa (1) pengaruh Debt To Total Asset Ratio (DAR) terhadap Net Profit Margin (NPM) tidak berpengaruh negatif dan tidak signifikan, (2) pengaruh Debt To Equity Ratio (DER) terhadap Net Profit Margin (NPM) tidak berpengaruh negatif dan signifikan, (3) pengaruh Debt To Total Asset Ratio (DAR) Dan Debt To Equity Ratio (DER) Terhadap Net Profit Margin (NPM) secara simultan dengan prob 0.102514 dan F-Statistic 2.332093 tidak berpengaruh positif dan tidak signifikan (4) pengaruh Net Profit Margin (NPM) terhadap Harga Saham berpengaruh positif dan tidak signifikan.

This study aims to determine the effect of Debt To Total Asset Ratio (DAR) and Debt To Equity Ratio (DER) on Net Profit Margin (NPM) and Its Impact on Stock Prices on Electronic Companies in the Tokyo Stock Exchange in 2007-2016.

The analytical method used is associative descriptive analysis. Data analysis includes data feasibility test, regression analysis, and hypothesis testing partially and simultaneously.

The results of this study indicate that (1) the effect of Debt To Total Asset Ratio (DAR) on Net Profit Margin (NPM) has no negative effect and is not significant, (2) the effect of Debt To Equity Ratio (DER) on Net Profit Margin (NPM) is not negative and significant effect, (3) the effect of Debt To Total Asset Ratio (DAR) and Debt To Equity Ratio (DER) on Net Profit Margin (NPM) simultaneously with prob 0.102514 and F-Statistic 2.332093 have no positive and insignificant effect (4) the influence of Net Profit Margin (NPM) on Stock Prices has positive and insignificant effect. 


\section{A. PENDAHULUAN}

\section{Latar Belakang}

Pertumbuhan ekonomi masyarakat diikuti dengan tuntutan pemenuhan kebutuhan dibidang elektronik yang juga meningkat terdapat banyak perusahaan elektronik yang ada di Indonesia, seperti Panasonic, Toshiba, Sanken, Sanyo, Sharp, Fujitsu, Olympus dan lain sebagainya dangan strategi perusahaan yang baik dan tepat sangat diperlukan agar perusahaan bisa menghadapi persaingan yang menjadi semakin ketat dan sulit seiring berjalannya waktu. Perusahaan dituntut untuk bisa dengan cepat bergerak mengikuti selera masyarakat yang terus berubah-ubah serta menghadapi strategi para pesaing yang terus berkembang dari waktu ke waktu. Apabila perusahaan ketinggalan dalam menghadapi perubahan yang terjadi, misalnya seperti selera konsumen yang terus berubah dan pekembangan teknologi yang terus meningkat maka perusahaan beresiko kehilangan pelangganya dan kalah dalam persaingan. Strategi perusahaan yang tepat juga sangat diperlukan agar perusahaan bisa mengambil langkah yang tepat untuk beroperasi secara efektif dan efisien dan untuk mendapat perhatian pelanggan atau konsumen yang nantinya bisa membawa profit yang maksimal.

Banyak Perusahaan Multinasional Jepang yang membuka cabang dan membangun industri di Indonesia. Survei Teikoku Data Bank (TDB) ini berdasarkan file pada laporan terhadap credit check report (CCR) sebanyak 1,6 juta perusahaan yang berinvestasi di perusahaan lokal Indonesia per Mei 2017, termasuk juga kantor perwakilan perusahaan Jepang yang ada di Indonesia. Hal ini tentu memberikan kontribusi pada pengurangan jumlah pengangguran di Indonesia karena keberadaan perusahaan Jepang yang membangun industri di Indonesia tentu membuka kesempatan kerja yang luas bagi sumber daya manusia dalam negeri. Perusahaan-perusahaan Jepang mempekerjakan lebih dari 32 ribu pekerja Indonesia, berdasarkan sumber yang didapat dari BPKM, ini menjadikan Jepang sebagai negara penyedia lapangan kerja nomor satu di Indonesia.

Melihat pada hubungan Indonesia dan Jepang, dapat kita lihat bahwa kepentingan ekonomi Jepang di Indonesia memberi dampak pada pertumbuhan ekonomi Indonesia. Industri elektronik memainkan peranan penting dalam mendongkrak investasi asing tersebut. Hubungan kerjasama di bidang ekonomi antara Jepang dan Indonesia telah terjalin lebih dari setengah abad. Selama itu pula, Jepang telah turut berperan dalam mendorong pembangunan ekonomi Indonesia. Peran Jepang dalam perekonomian Indonesia dapat ditinjau dari tiga aspek, meliputi sektor perdagangan, investasi, dan kerjasama ekonomi. Di bidang perdagangan internasional (ekspor-impor), Jepang adalah mitra dagang terbesar Indonesia. Begitu pula halnya dengan bidang investasi, investorinvestor Jepang memainkan peran terbesar dalam penanaman modal langsung (foreign direct investment) dengan membangun elektronik melalui perusahaan multinasional. Kemudian, Jepang juga memberikan bantuan dalam jumlah yang besar dalam skema kerjasama ekonomi sebagai upaya mendukung pembangunan di Indonesia.

Bursa Saham Tokyo (bahasa Jepang: Tōkyō Shōken Torihikijo, bahasa Inggris: Tokyo Stock Exchange, 'TSE') adalah bursa saham yang terletak di Tokyo, Jepang. Didirikan pada 15 Mei 1878, dan perdagangan dimulai di sana pada 1 Juni pada tahun yang sama. Bursa ini ditutup selama Perang Dunia II; setelah pengorganisasian kembali, perdagangan dilanjutkan pada 16 Mei 1949. Pada 18 Januari 2006, akibat dugaan penggelapan uang di perusahaan Internet besar bernama Live door, terjadi penjualan saham besar-besaran yang mengakibatkan TSE untuk pertama kalinya ditutup lebih awal karena volume perdagangan pada hari tersebut telah mencapai jumlah yang hampir melampaui kapasitas sistem komputer di TSE sebesar 4,5 juta perdagangan per hari. 
Dalam perhitungan analisis fundamental, perbandingan antara utang (debt) dan harta (asset) dikenal dengan istilah Debt to Total Asset Ratio (DAR) Cara menghitungnya yaitu total utang dibagi total asset lalu dikalikan 100\%, sedangkan perbandingan antara utang (debt) dan modal (equity) dikenal dengan istilah Debt to Equity Ratio (DER) cara menghitungnya yaitu total utang dibagi total modal lalu dikalikan $100 \%$. Utang yang jumlahnya lebih kecil dari modal dan hartanya masih bisa dibilang baik, alias Debt to Equity Ratio (DER) dan Debt to Total Asset Ratio (DAR) nya dibawah 100\%. Jika Debt to Total Asset Ratio (DAR) dan Debt to Equity Ratio (DER) nya diatas 100\% sudah pasti utang tersebut tidak baik, dengan catatan utang-utang tersebut bukan merupakan utang yang berbahaya, melainkan utang yang memang mendukung perusahaan untuk membayar bunga atau denda jika terlambat membayar.

Debt to Total Asset Ratio (DAR) merupakan rasio utang yang digunakan untuk mengukur perbandingan antara total utang dengan total aktiva. Dengan kata lain, seberapa besar aktiva perusahaan dibiayai oleh utang atau seberapa besar utang perusahaan berpengaruh terhadap pengelolaan aktiva. (Kasmir, 2014:156).

Debt to Equity Ratio (DER) merupakan perbandingan rasio yang digunakan untuk menilai utang dengan ekuitas. Rasio ini dicari dengan cara membandingkan antara seluruh utang, termasuk utang lancar dengan seluruh ekuitas. Rasio ini berguna untuk mengetahui jumlah dana yang disediakan peminjam (kreditor) dengan pemilik perusahaan. Dengan kata lain, rasio ini berfungsi untuk mengetahui setiap rupiah modal sendiri yang dijadikan untuk jaminan utang. (Kasmir, 2014:157).

Menurut Kasmir, menyatakan bahwa Net Profit Margin (NPM) merupakan ukuran keuntungan yang membandingkan antara laba setelah bunga dan pajak dibandingkan dengan penjulan. Rasio ini menunjukkan pendapatan bersih perusahaan atas penjulan. Rasio ini juga dibandingkan dengan rata-rata industri. (Kasmir, 2014:200). Penggunaan rasio Profitabilitas dapat dilakukan dengan menggunakan perbandingan antara berbagai komponen yang ada di laporan keuangan, terutama laporan keuangan neraca dan laporan laba rugi. Pengukuran dapat dilakukan untuk beberapa periode operasi. Tujuannya adalah agar terlihat perkembangan perusahaan dalam rentang waktu tertentu, baik penurunan atau kenaikan, sekaligus mencari penyebab perusahaan tersebut.

Harga saham merupakan harga penutupan pasar saham selama periode pengamatan untuk tiap-tiap jenis saham yang dijadikan sampel dan pergerakannya senantiasa diamati oleh para investor. Salah satu konsep dasar dalam manajemen keuangan adalah bahwa tujuan yang ingin dicapai manajemen keuangan adalah memaksimalisasi nilai perusahaan. Bagi perusahaan yang telah go public, tujuan tersebut dapat dicapai dengan cara memaksimalisasi nilai pasar harga saham yang bersangkutan. Dengan demikian pengambilan keputusan selalu didasarkan pada pertimbangan terhadap maksimalisasi kekayaan para pemegang saham. Sartono (2008:70) menyatakan bahwa: "Harga saham terbentuk melalui mekanisme permintaan dan penawaran di pasar modal. Apabila suatu saham mengalami kelebihan permintaan, maka harga saham cenderung naik. Sebaliknya, apabila kelebihan penawaran maka harga saham cenderung turun".

Menurut Jogiyanto (2008:167) pengertian dari harga saham adalah "Harga suatu saham yang terjadi di pasar bursa pada saat tertentu yang ditentukan oleh pelaku pasar dan ditentukan oleh permintaan dan penawaran saham yang bersangutan di pasar modal". Menurut Brigham dan Houston (2010:7) harga saham adalah "Harga saham menentukan kekayaan pemegang saham. Maksimalisasi kekayaan pemegang saham diterjemahkan menjadi maksimalkan harga saham perusahaan. Harga saham pada satu waktu tertentu akan bergantung pada arus kas yang diharapkan diterima di masa depan oleh investor "rata-rata" jika investor membeli saham". 
Berdasarkan pengertian para ahli diatas maka dapat disimpulkan bahwa harga saham adalah harga yang terbentuk sesuai permitaan dan penawaran dipasar jual beli saham dan biasanya merupakan harga penutupan. Berikut ini adalah data Debt to Total Asset Ratio (DAR), Debt to Equity Ratio (DER), Net Profit Margin (NPM) dan Harga Saham Perusahaan Elektronik Jepang dalam mencapai efisiensi finansial perusahaannya. Berikut data indicator variabel sebagai berikut:

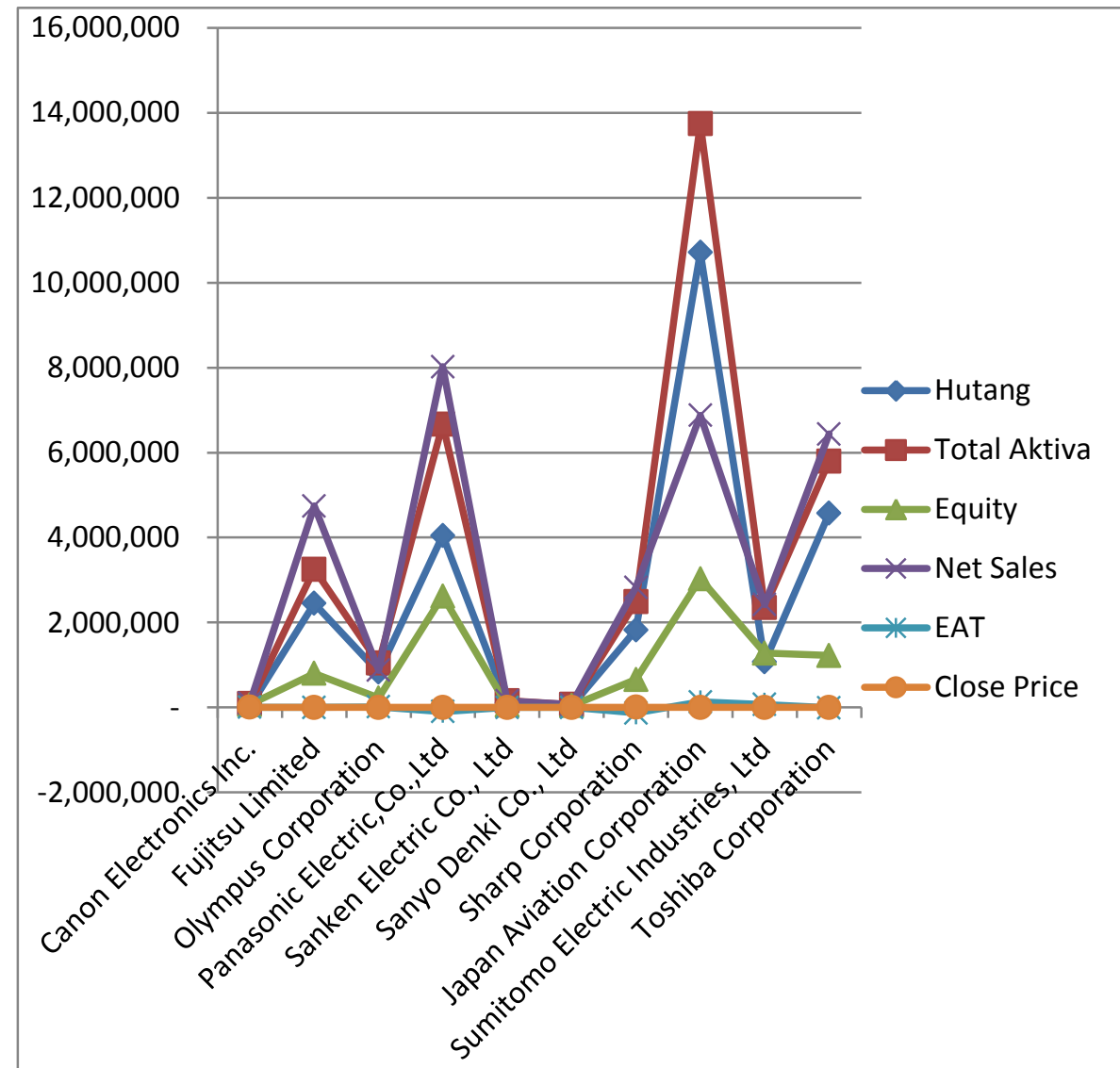

\section{Grafik 1.1. \\ Indikator Data Penelitian \\ Rata-rata Variabel Perusahaan}

Berdasarkan Grafik 1.1 di atas menunjukkan bahwa pada 10 perusahaan elektronik di Bursa Efek Jepang dari tahun 2007 ke 2016 mengalami fluktuasi dari indikator variabel seperti pada indikator hutang pada 10 perusahaan elektronik mengalami penurunan antara lain Canon Electronics Inc., Fujitsu Limited, Olympus Corporation, penurunan jumlah utang ini menunjukkan perusahaan mampu membayar utang-utang di setiap tahunnya Total asset perusahaan juga mengalami penurunan seperti pada Panasonic Electric Co.,Ltd, Sanken Electric Co., Ltd, Sanyo Denki Co., Ltd, Sharp Corporation,. Selanjutnya pada equity atau modal pada 10 mengalami fluktuasi modal namun penurunan terlihat pada Fujitsu Limited, Panasonic Electric Co.,Ltd, Sanken Electric Co., Ltd, Sharp Corporation,. Dari sisi penjualan (Sales) juga mengalami fluktuasi namun penurunan yang terlihat pada Canon Electronics Inc., Fujitsu Limited, Olympus Corporation, Panasonic Electric Co.,Ltd, Sanyo Denki Co., Ltd, Sharp Corporation, Japan Aviation Corporation, Toshiba Corporation, penurunan jumlah penjualan ini menunjukkan perusahaan belum mampu meningkatkan omezet penjualan di setiap tahunnya sedangkan Earning after tax (EAT) fluktuasi penurunan laba terjadi pada Fujitsu Limited, Olympus Corporation, Panasonic Electric Co.,Ltd, Sanken Electric Co., Ltd, Sanyo Denki Co., Ltd, 
Sharp Corporation, Japan Aviation Corporation, Toshiba Corporation. penurunan jumlah Earning after tax (EAT) ini menunjukkan perusahaan mengalami kerugian yang mengakibatkan laba menjadi negatif di setiap tahunnya, demikian juga dengan profit margin (NPM) mengalami fluktuasi penurunan laba se terjadi pada Fujitsu Limited, Olympus Corporation, Panasonic Electric Co.,Ltd, Sanken Electric Co., Ltd, Sanyo Denki Co., Ltd, Sharp Corporation, Japan Aviation Corporation, Toshiba Corporation.

Unit analisis dalam penelitian ini adalah 10 perusahaan elektronik terbesar di Jepang yaitu Canon Electronics Inc., Fujitsu Limited, Olympus Corporation, Panasonic Electric Co.,Ltd, Sanken Electric Co., Ltd, Sanyo Denki Co., Ltd, Sharp Corporation, Japan Aviation Corporation, Sumitomo Electric Industries, Ltd, Toshiba Corporation. Alasan dipilihnya perusahaan ini, karena ke 10 perusahaan termasuk pada perusahaan yang bergerak di bidang elektronik yang terdaftar di Tokyo Stock Exchange (TSE) atau Bursa Saham Tokyo .

Alasan peneliti memilih Debt to Equity Ratio (DER) dan Debt to Total Asset Ratio (DAR) merupakan indikator utang yang sering diperhatikan oleh investor dimana Utang yang jumlahnya lebih kecil dari modal dan hartanya masih bisa dibilang baik, alias Debt to Total Asset Ratio (DAR) dan Debt to Equity Ratio (DER) nya dibawah $100 \%$. Jika Debt to Total Asset Ratio (DAR) dan Debt to Equity Ratio (DER) nya diatas 100\% sudah pasti utang tersebut tidak baik, dengan catatan utang-utang tersebut bukan merupakan utang yang berbahaya, melainkan utang yang memang mendukung perusahaan untuk membayar bunga atau denda jika terlambat membayar.

Alasan peneliti memilih Net Profit Margin (NPM) karena ingin melihat seberapa besar efektifitas perusahaan dalam menghasilkan laba dari keseluruhan operasi aktivitas perusahaan. dan nilai Net Profit Margin (NPM) yang fluktuatif memberikan dasar penilaian seorang investor untuk melakukan investasinya.

Alasan peneliti memilih harga saham, dalam hal ini adalah harga saham menjadi bagian penting dari strategi pendanaan jangka panjang perusahaan karena nilai saham mewakili nilai perusahaan, tidak hanya nilai intrinsik suatu saat tetapi juga adalah harapan kemampuan perusahaan dalam meningkatkan kesejahteraan pemegang saham yang digunakan sebagai model penilaian saham untuk mengestimasi dividen yang dibayarkan pada masa yang akan datang kepada para pemegang saham.

Berdasarkan latar belakang masalah di atas, maka peneliti tertarik untuk melakukan penelitian dengan memfokuskan pada perusahaan Elektronik di Bursa Saham Tokyo dalam sebuah penelitian dengan judul "PENGARUH DEBT TO TOTAL ASSET RATIO (DAR) DAN DEBT TO EQUITY RATIO (DER) TERHADAP NET PROFIT MARGIN (NPM) SERTA DAMPAKNYA TERHADAP HARGA SAHAM PADA PERUSAHAAN ELEKTRONIK DI BURSA SAHAM TOKYO PERIODE 2007-2016"

\section{Perumusan Masalah}

Berdasarkan identifikasi masalah dan pembatasan masalah yang diuraikan sebelumnya, maka perumusan masalah-masalah yang akan di teliti dirumuskan sebagai berikut :

1) Bagaimana pengaruh Debt to Total Asset Ratio (DAR) terhadap Net Profit Margin (NPM) pada Perusahaan Elektronik Jepang di Bursa Efek Tokyo?

2) Bagaimana pengaruh Debt to Equity Ratio (DER) terhadap Net Profit Margin (NPM) pada Perusahaan Elektronik Jepang di Bursa Efek Tokyo?

3) Bagaimana pengaruh Debt to Total Asset Ratio (DAR) dan Debt to Equity Ratio (DER) terhadap Net Profit Margin (NPM) pada Perusahaan Elektronik Jepang di Bursa Efek Tokyo? 
4) Bagaimana pengaruh Net Profit Margin (NPM) terhadap Harga Saham pada Perusahaan Elektronik Jepang di Bursa Efek Tokyo?

\section{B. KAJIAN LITERATUR}

\section{Teori Tentang Debt to Total Asset Ratio (DAR)}

Menurut Syamsuddin (2006:30), menyatakan bahwa "Debt to total Assets Ratio (DAR) digunakan untuk mengukur seberapa besar jumlah aktiva perusahaan dibiayai dengan total hutang. Semakin tinggi rasio ini berarti semakin besar jumlah modal pinjaman yang digunakan untuk investasi pada aktiva guna menghasilkan keuntungan bagi perusahaan."

Menurut Sawir (2008:13) debt ratio merupakan rasio yang memperlihatkan proposi antara kewajiban yang dimiliki dan seluruh kekayaan yang dimiliki.

Menurut Kasmir (2014:156) menyatakan bahwa "Debt to Asset Ratio (DAR) merupakan rasio utang yang digunakan untuk mengukur perbandingan antara total utang dengan total aktiva. Dengan kata lain, seberapa besar aktiva perusahaan dibiayai oleh utang atau seberapa besar utang perusahaan berpengaruh terhadap pengelolaan aktiva."

Berdasarkan beberapa definisi yang telah diuraikan, maka Debt to Asset Ratio (DAR) adalah rasio yang mengukur seberapa jauh perusahaan dibiayai oleh hutang dan kemampuan perusahaan untuk memenuhi kewajibannya dengan aktiva atau asset yang dimiliki. Rasio ini dapat diukur dengan membandingkan jumlah aktiva dengan jumlah utang (baik jangka pendek maupun jangka panjang).

\section{Teori Tentang Debt to Equity Ratio (DER)}

Pengertian Debt to Equity Ratio (DER) menurut Darsono dan Ashari (2010:5455) yaitu: Debt to Equity Ratio (DER) merupakan salah satu rasio leverage atau solvabilitas. Rasio solvabilitas adalah rasio untuk mengetahui kemampuan perusahaan dalam membayar kewajiban jika perusahaan tersebut dilikuidasi.Rasio ini juga disebut dengan rasio pengungkit (Leverage) yaitu menilai batasan perusahaan dalam meminjam uang.

Horne dan Machowicz yang dialih bahasakan oleh Fitriasari dan Kwary (2009:182) mengemukakan bahwa "leverage merupakan penggunaan biaya tetap dalam usaha untuk meningkatkan (level up) profitabilitas". Sedangkan pengertian Debt to Equity Ratio (DER) menurut Gibson (2008:260) yaitu "Debt equity ratio is another computation thats determines the entity's long-term debt-paying ability". Artinya, Rasio utang terhadap ekuitas adalah komputasi lain yang menentukan kemampuan membayar utang jangka panjang suatu entitas.

Menurut Sugiyono (2011:71), menyatakan bahwa: "Rasio ini menunjukan perbandingan hutang dan modal. Rasio ini merupakan salah satu rasio penting karena berkaian dengan masalah trading on equiy, yang dapat memberikan pengaruh positif dan negatif terhadap rentabilitas modal sendiri dan perusahaan tersebut".

Siegel dan Shim dalam Fahmi (2012:128) mendefinisikan debt to equity ratio, "Ukuran yang dipakai dalam menganalisis laporan keuangan untuk memperlihatkan besarnya jaminan yang tersedia untuk kreditor".

Sedangkan menurut Kasmir (2014:157), menyatakan bahwa: "Debt to equity ratio merupakan rasio yang digunakan untuk menilai hutang dengan ekuitas."

Berdasarkan beberapa definisi yang telah diuraikan, dapat maka yang dimaksud Debt to Equity Ratio (DER) merupakan rasio yang mengukur seberapa jauh perusahaan dibiayai oleh hutang dan kemampuan perusahaan untuk memenuhi kewajibannya dengan ekuitas yang dimiliki. 


\section{Teori Tentang Net Profit Margin (NPM)}

Menurut Kasmir (2014:200), menyatakan bahwa Net Profit Margin (NPM) merupakan ukuran keuntungan yang membandingkan antara laba setelah bunga dan pajak dibandingkan dengan penjulan. Rasio ini menunjukkan pendapatan bersih perusahaan atas penjulan. Rasio ini juga dibandingkan dengan rata-rata industri.

Menurut Werner R. Murhadi (2013:64) Net Profit Margin adalah mencerminkan kemampuan perusahaan dalam menghasilkan laba neto dari setiap penjualannya. Semakin tinggi nilai NPM maka menunjukkan semakin baik. Berdasarkan definisi di atas maka dapat disimpulkan bahwa Net Profit Margin adalah kemampuan perusahaan untuk memperoleh laba di setiap penjualan yang telah di kurangi bunga dan pajak disetiap periode.

Menurut Riyanto (2010:37) Profit margin yaitu perbandingan antara net operating income dengan net sales.Pengertian Profit Margin menurut Munawir (2010:89) Profit margin ini mengukur tingkat keuntungan yang dapat dicapai oleh perusahaan dihubungkan dengan penjualannya. Net Profit Margin (NPM) menggambarkan besarnya laba bersih yang diperoleh perusahaan pada setiap penjualan yang dilakukan. Dengan kata lain rasio ini mengukur laba bersih setelah pajak terhadap penjualan.

Disimpulkan bahwa Net Profit Margin (NPM) besarnya laba bersih yang diperoleh perusahaan pada setiap menggambarkan penjualan yang dilakukan. Dengan kata lain rasio ini mengukur laba bersih setelah pajak terhadap penjualan. Apabila kinerja keuangan perusahaan dalam menghasilkan laba bersih atas penjualan semakin meningkat maka hal ini akan berdampak pada meningkatnya pendapatan yang akan diterima oleh para pemegang saham.

\section{Teori Tentang Harga Saham}

Pengertian harga saham menurut Jogiyanto (2010), adalah: terjadi dipasar bursa pada saat tertentu yang ditentukan oleh pelaku pasar dan 9 ditentukan oleh permintaan dan penawaran saham yang bersangkutan dipasar modal. Menurut Widoatmojo (1996) dalam Satria (2008) harga saham dapat dibedakan menjadi 3 (tiga):

a). Harga Nominal Harga yang tercantum dalam sertifikat saham yang ditetapkan oieh emiten untuk menilai setiap lembar saham yang dikeluarkan. Besarnya harga nominal memberikan arti penting saham karena dividen minimal biasanya ditetapkan berdasarkan nilai nominal.

b). Harga Perdana Harga ini merupakan harga pada waktu harga saham tersebut dicatat di bursa efek. Harga saham pada pasar perdana biasanya ditetapkan oleh penjamin emisi (underwriter) dan emiten. Dengan demikian akan diketahui berapa harga saham emiten itu akan dijual kepada masyarakat biasanya imtuk menentukan harga perdana.

c). Harga pasar Kalau harga perdana merupakan harga jual dari perjanjian emisi kepada investor, maka harga pasar adalah harga jual dari investor yang satu dengan investor yang lain. Harga ini terjadi setelah saham tersebut dicatatkan di bursa. Transaksi disini tidak lagi melibatkan emiten dan penjamin emisi harga ini yang disebut sebagai harga di pasar sekunder dan harga inilah yang benar- benar mewakili harga perusahaan penerbitnya, karena pada transaksi di pasar sekunder, kecil sekali terjadi negosiasi harga investor dengan perusahaan penerbit. Harga yang setiap hari diumumkan di surat kabar atau media lain adalah harga pasar.

\section{Bursa Saham Tokyo}

Bursa Saham Tokyo (bahasa Jepang: Tōkyō Shōken Torihikijo, bahasa Inggris: Tokyo Stock Exchange, 'TSE') Didirikan pada 15 Mei 1878, dan perdagangan 
dimulai di sana pada 1 Juni pada tahun yang sama. Bursa ini ditutup selama Perang Dunia II; setelah pengorganisasian kembali, perdagangan dilanjutkan pada 16 Mei 1949. Pada 18 Januari 2006, akibat dugaan penggelapan uang di perusahaan Internet besar bernama Livedoor, terjadi penjualan saham besar-besaran yang mengakibatkan TSE untuk pertama kalinya ditutup lebih awal karena volume perdagangan pada hari tersebut telah mencapai jumlah yang hampir melampaui kapasitas sistem komputer di TSE sebesar 4,5 juta perdagangan per hari.

Ada alternatif investasi dalam perdagangan saham yang dapat meminimalkan risiko dan akan melindungi dari fluktuasi harga yang merugikan, jenis investasi ini disebut Kontrak Berjangka atau Index Futures. Kontrak berjangka adalah suatu kewajiban untuk menerima atau untuk memberikan suatu instrumen keuangan atau kontrak di masa depan dengan menggunakan harga yang telah disepakati pada hari ini. Di dalam perdagangan indeks berjangka investor diberikan peluang untuk mengambil posisi open sell atau menutup posisi open sell kontrak didasari oleh adanya harapan bahwa harga akan turun atau investor bisa juga mengambil posisi open buy dan melikuidasi posisi open buy kontrak didasari adanya harapan bahwa harga akan naik. Top growth Futures menawarkan investasi pada indeks berjangka untuk mencari keuntungan dari fluktuasi harga indeks. Indeks Berjangka yang ditawarkan adalah Indeks Berjangka Jepang (Nikkei 225), Indeks Berjangka Hongkong (Hang Seng) dan Indeks Berjangka Korea (Kospi 200).

\section{METODOLOGI PENELITIAN}

Menurut Sugiyono (2014:96), hipotesis merupakan jawaban sementara terhadap rumusan masalah penelitian, di mana rumusan masalah penelitian telah dinyatakan dalam bentuk pertanyaan, berdasarkan pada teori-teori yang relevan tetapi belum didasarkan fakta-fakta empiris yang di peroleh dari pengumpulan data.

\section{Ruang Lingkup Penelitian}

\section{a) Tempat Penelitian}

Penelitian ini dilakukan di rumah peneliti, di kampus Universitas Pamulang serta via internet dengan data annual report setiap perusahaan pada Bursa Efek Tokyo (disingkat TSE, atau Tokyo Stock Exchange) Bursa Saham Tokyo adalah bursa saham yang terletak di Tokyo, Jepang. Didirikan pada 15 Mei 1878, dan perdagangan dimulai di sana pada 1 Juni pada tahun yang sama, melalui website: www.jpx.co.jp. Peneliti mengambil data sekunder laporan keuangan perusahaan elektronik yang terdaftar di Bursa Efek Tokyo Periode 2007-2016 sebanyak 10 Perusahaan, melalui annual report perusahaan.

\section{b) Waktu Penelitian}

Waktu penelitian dimulai dengan mengolah data laporan keuangan perusahaan elektronik yang terdaftar di Bursa Efek Tokyo pada periode 2007-2016 dilakukan penelitian dan pengolahan data pada bulan Januari 2018 sampai dengan bulan Juni 2018.

\section{c) Metode Penelitian}

Penelitian ini dilakukan untuk memperoleh informasi tentang bagaimana analisis pengaruh Debt to Total Asset Ratio (DAR) dan Debt to Equity Ratio (DER) terhadap Net Profit Margin (NPM) dan dampaknya terhadap Harga Saham (Studi Kasus pada Perusahaan Elektronik di Bursa Efek Tokyo Periode 2007-2016), sesuai maksus tersebut, maka metode penelitian yang digunakan adalah asosiatif kausal analitis.

Dalam penelitian ini penulis menggunakan metode penelitian studi empiris dengan pendekatan deskriptif kuantitatif dan asosiatif, karena adanya variabel-variabel yang akan ditelaah hubungannya serta tujuannya untuk menyajikan gambaran secara terstruktur, faktual, mengenai fakta-fakta serta hubungan antar variabel yang diteliti. 


\section{Populasi dan Sampel}

\section{a) Populasi Penelitian}

Populasi adalah wilayah generalisasi yang terdiri atas objek atau subjek yang mempunyai kualitas dan karakteristik tertentu yang di tetapkan oleh peneliti untuk dipelajari dan ditarik kesimpulannya (Sugiyono, 2014;115).

Populasi pada penelitian ini adalah seluruh perusahaan elektronik yang terdaftar di Bursa Efek Tokyo pada tahun 2007-2016, dengan total populasi perusahaan yang terdaftar sebanyak 35 perusahaan yaitu Sony, Casio, Hitachi, Toshiba, NEC, TDK, JAE, JVC, Panasonic, Roland, Fujitsu, Canon, Sharp, Fujifilm, Rohm, Plextor, Korg, Pioneer, Kyocera, Minolta, Maxell, Mitsubishi, Tachnics, Riooh, Pentax, Olympus, Nitendo, Sanyo, Epson, Nikon, Yamaha, Seiko, Citizen Watch, Kenwood, Sumitomo.

\section{b) Sampel Penelitian}

Model sampel yang digunakan pada penelitian ini adalah teknik non probability sampling yang digunakan dalam pengambilan sampel pada penelitian ini yaitu teknik purposive sampling. Pengertian purposive sampling menurut Sugiyono (2014:122) adalah "Teknik penentuan sampel dengan pertimbangan tertentu. yang merupakan teknik pengambilan sampel non random sampling." Non random sampling mempunyai arti bahwa pengambilan sampel yang tidak semua anggota populasi mendapat kesempatan untuk dipilih menjadi sampel. Metode purposive sampling harus menentukan kriteria yang ditentukan untuk mendapatkan sampel yang representative. Kriteria yang ditetapkan dalam pengambilan sampel pada penelitian ini ditentukan sebagai berikut :

1) Perusahaan Elektronik yang menerbitkan laporan keuangan tahun 2007 sampai 2016.

2) Perusahaan yang memiliki nilai Debt to Asset Ratio (DAR) dan Debt to Equity Ratio (DER) terhadap Net Profit Margin (NPM) dan Harga Saham.

Persyaratan untuk dijadikan sampel dengan kriteria perusahaan elektronik yang tertera di atas dapat di peroleh sampel pada penelitian ini sebanyak 10 perusahaan sebagai berikut:

Tabel 3.1

Sampel Perusahaan Elektronik yang terdaftar di Bursa Efek Tokyo

\begin{tabular}{|c|c|l|}
\hline No. & $\begin{array}{c}\text { Kode } \\
\text { Perusahaan }\end{array}$ & \multicolumn{1}{c|}{ Nama Perusahaan } \\
\hline 1 & 7751 & Canon Electronics Inc. \\
\hline 2 & 6702 & Fujitsu Limited \\
\hline 3 & 7733 & Olympus Corporation \\
\hline 4 & 6752 & Panasonic Electric,Co.,Ltd \\
\hline 5 & 6707 & Sanken Electric Co., Ltd \\
\hline 6 & 6516 & Sanyo Denki \\
\hline 7 & 6753 & Sharp Corporation \\
\hline 8 & 6807 & Japan Aviation Corporation \\
\hline 9 & 5802 & Sumitomo Electric Industries, Ltd \\
\hline 10 & 6502 & Toshiba Corporation \\
\hline
\end{tabular}

Sumber : www.jpx.co.jp/, 2018) 


\section{HASIL DAN PEMBAHASAN}

\section{Analisis Data}

Analisa data yang akan digunakan dalam penelitian ini adalah Perusahaan Elektronik di Bursa Efek Tokyo (TSE) periode 2007-2016 yang memenuhi kriteria tertentu. Data yang diperoleh akan diolah sesuai dengan kepentingan penelitian dan selanjutnya akan disajikan dalam bentuk tabel untuk mengetahui nilai Debt to Asset Ratio (DAR) (X1) dan Debt to Equity Ratio (DER) (X2) terhadap Net Profit Margin (NPM) (Y) dan Harga Saham(Z). Rancangan analisis yang di pakai dalam penelitian ini adalah sebagai beikut:

\section{a) Analisis Regresi Linier Berganda}

Analisis ini digunakan untuk memprediksi nilai dari variabel dependen apabila nilai variabel independen mengalami penurunan atau kenaikan, dan untuk mengetahui arah hubungan antara variabel independen dengan variabel dependen apakah masing-masing variabel independen berhubungan positif atau negatif dengan variabel dependen.

Rumus persamaan regresi linier berganda yang digunakan adalah sebagai berikut:

$\mathrm{Y}=\mathrm{a}+\mathrm{b} 1 \mathrm{X} 1+\mathrm{b} 2 \mathrm{X} 2+\mathrm{e}$

\section{Keterangan:}

$\mathrm{Y} \quad=\quad$ Net Profit Margin (NPM)

$\mathrm{a}=$ Konstanta

$b_{1} \ldots b_{2}=\quad$ Koefisien Regresi Variabel Independen

$\mathrm{X}_{1}=\quad$ Variabel Debt to Asset Ratio (DAR)

$\mathrm{X}_{2} \quad=\quad$ Variabel Debt to Equity Ratio (DER)

$\mathrm{e}=$ Variabel lain yang tidak diteliti

\section{b) Analisis Koefisien Determinasi}

Koefisien determinasi merupakan suatu ukuran yang penting dalam regresi karena dapat menginformasikan baik atau tidak nya model regresi yang terestimasi atau dengan kata lain angka tersebut dapat mengukur seberapa dekat garis regresi yang terestimasi dengan data sesungguhnya. Koefisien ini menunjukan seberapa besar persentase variabel independenyang digunakan dalam model mampu menjelaskan variabel dependen koefisien determinasi.

1) Koefisien Determinasi Debt to Total Assset Ratio (DAR) dan Debt to Equity Ratio (DER) terhadap Net Profit Margin (NPM). Berdasarkan tabel 4.21 besarnya angka $R$ Squared adalah 0.877423 . Hal ini menunjukan bahwa presentase variabel Debt to Total Assset Ratio (DAR) dan Debt to Equity Ratio (DER) terhadap Net Profit Margin (NPM) adalah sebesar $87.74 \%$ sedangkan sisanya $12,26 \%$ dipengaruhi factor lain.

2) Koefisien Determinasi Net Profit Margin (NPM) terhadap Harga Saham. Berdasarkan tabel 4.28 besarnya angka $R$-Squared adalah 0.781800 . Hal ini menunjukan bahwa presentase variabel Net Profit Margin (NPM) terhadap Harga Saham adalah sebesar $78,18 \%$ sedangkan sisanya $21,82 \%$ dipengaruhi faktor lain.

\section{c) Uji Regresi Data Panel}

Program EVIEWS 9.0 bisa melakukan uji regresi data panel. Hanya saja terbatas yang bisa diuji model pool/common dan model fix baik dengan time series yang tetap atau efek cross section yang tetap. Syarat untuk melakukan uji data panel dengan menggunakan program EVIEWS 9.0 adalah dengan membuat variabel dummy sebagai cross section atau variabel intercept nya. Cara ini dilakukan karena dianggap lebih mudah dan menghasilkan hasil analisis keseluruhan berupa output sekaligus dalam satu kali uji saja. Sebagai pembanding hasilnya, maka dilakukan analisis regresi data panel dengan menggunakan program EVIEWS 9.0 juga. 
Dalam metode estimasi model regresi dengan menggunakan data panel dapat dilakukan melalui tiga pendekatan, antara lain:

1) Common Effect Model

Merupakan pendekatan model data panel yang paling sederhana karena hanya mengkombinasikan data time series dan cross section. Pada model ini tidak diperhatikan dimensi waktu maupun individu, sehingga diasumsikan bahwa perilaku data perusahaan sama dalam berbagai kurun waktu. Metode ini bisa menggunakan pendekatan Ordinary Least Square (OLS) atau teknik kuadrat terkecil untuk mengestimasi model data panel.

2) Fixed Effect Model

Model ini mengasumsikan bahwa perbedaan antar individu dapat diakomodasi dari perbedaan intersepnya. Untuk mengestimasi data panel model Fixed Effects menggunakan teknik variable dummy untuk menangkap perbedaan intersep antar perusahaan, perbedaan intersep bisa terjadi karena perbedaan budaya kerja, manajerial, dan insentif. Namun demikian slopnya sama antar perusahaan. Model estimasi ini sering juga disebut dengan teknik Least Squares Dummy Variable (LSDV).

3) Random Effect Model

Model ini akan mengestimasi data panel dimana variabel gangguan mungkin saling berhubungan antar waktu dan antar individu. Pada model Random Effect perbedaan intersep diakomodasi oleh error terms masing-masing perusahaan. Keuntungan menggunkan model Random Effect yakni menghilangkan heteroskedastisitas. Model ini juga disebut dengan Error Component Model (ECM) atau teknik Generalized Least Square (GLS).

Untuk memilih model yang paling tepat digunakan dalam mengelola data panel, terdapat beberapa pengujian yang dapat dilakukan yakni:

a) Uji Chow, yakni pengujian untuk menentukan model Fixed Effet atauRandom Effect yang paling tepat digunakan dalam mengestimasi data panel.

b) Uji Hausman adalah pengujian statistik untuk memilih apakah model Fixed Effect atau Random Effect yang paling tepat digunakan.

c) Uji Lagrange Multiplier untuk mengetahui apakah model Random Effect lebih baik daripada metode Common Effect (OLS) digunakan uji Lagrange Multiplier (LM).

Tabel 4.23

Kesimpulan Pengujian Model Regresi Data Panel

\begin{tabular}{|l|l|l|l|}
\hline No & Metode & Pengujian & Hasil \\
\hline 1. & Chow-Test & Common Effect vs Fixed Effect & Fixed Effect \\
\hline 2. & Hausman Test & Fixed Effect vs Random Effect & Random Effect \\
\hline 3. & LM Test & Common Effect vs Random Effect & Random Effect \\
\hline
\end{tabular}

Sumber : data yang diolah (2018)

Berdasarkan pengujian berpasangan terhadap ketiga model regresi data panel dapat disimpulkan bahwa model Random Effect dalam regresi data panel yang digunakan lebih lanjut dalam mengestimasi faktor-faktor yang mempengaruhi Net Profit Margin (NPM) terhadap 10 perusahaan elektronik yang dijadikan sampel dalam penelitian ini selama periode 2007-2016.

\section{3) Rancangan Pengujian Hipotesis}

Hipotesis adalah jawaban sementara terhadap rumusan masalah pada suatu penelitian yang akan dilakukan. Atau dapat diartikan hipotesis adalah kesimpulan atau pernyataan 
sementara terhadap suatu permasalahan yang terjadi dalam penelitian yang sebenarnya masih perlu dibuktikan melalui data yang terkumpul.

a) Pengujiam Hipotesis Secara Parsial (Uji t)

Pengujian ini dilakukan dengan menggunakan uji t untuk mengetahui pengaruh dari tiaptiap variabel, dengan membandingkan t hitung dan $t$ tabel.

1). Variabel Debt to Total Asset Ratio (DAR)

$\mathrm{H}_{\circ}$ 1: Tidak terdapat pengaruh antara Debt to Total Asset Ratio

(DAR) terhadap Net Profit Margin (NPM).

$\mathrm{H}_{\mathrm{a}} 1$ : Terdapat pengaruh antara Debt to Total Asset Ratio (DAR)

terhadap Net Profit Margin (NPM).

\begin{tabular}{|c|c|c|c|c|}
\hline \multicolumn{5}{|c|}{$\begin{array}{l}\text { Pengaruh variabel Debt to Total Asset Ratio (DAR } \\
\quad \text { Net Profit Margin (NPM) } \\
\text { Dependent Variable: NPM } \\
\text { Method: Panel EGLS (Cross-section random effects) } \\
\text { Date: } 08 / 01 / 18 \text { Time: } 23: 19 \\
\text { Sample: } 20072016 \\
\text { Periods included: } 10 \\
\text { Cross-sections included: } 10 \\
\text { Total panel (balanced) observations: } 100 \\
\text { Swamy and Arora estimator of component variances }\end{array}$} \\
\hline Variable & Coefficient & Std. Error & t-Statistic & Prob. \\
\hline $\begin{array}{c}\mathrm{C} \\
\mathrm{DAR}\end{array}$ & $\begin{array}{r}17.29379 \\
-1.069197\end{array}$ & $\begin{array}{l}6.013861 \\
0.710480\end{array}$ & $\begin{array}{r}2.875655 \\
-1.504895\end{array}$ & $\begin{array}{l}0.0049 \\
0.1356\end{array}$ \\
\hline \multicolumn{5}{|c|}{ Effects Specification } \\
\hline $\begin{array}{l}\text { Cross-section rando } \\
\text { Idiosyncratic random }\end{array}$ & & & $\begin{array}{l}4.813101 \\
1.846301\end{array}$ & $\begin{array}{l}0.8717 \\
0.1283\end{array}$ \\
\hline \multicolumn{5}{|c|}{ Weighted Statistics } \\
\hline $\begin{array}{l}\text { R-squared } \\
\text { Adjusted R-squared } \\
\text { S.E. of regression } \\
\text { F-statistic } \\
\text { Prob(F-statistic) }\end{array}$ & $\begin{array}{l}0.022274 \\
0.012298 \\
1.859523 \\
2.232617 \\
0.138338\end{array}$ & $\begin{array}{l}\text { Mean depe } \\
\text { S.D. deper } \\
\text { Sum squar } \\
\text { Durbin-Wa }\end{array}$ & $\begin{array}{l}\text { ndent var } \\
\text { dent var } \\
\text { ed resid } \\
\text { tson stat }\end{array}$ & $\begin{array}{l}1.028719 \\
1.871063 \\
338.8669 \\
1.953499\end{array}$ \\
\hline \multicolumn{5}{|c|}{ Unweighted Statistics } \\
\hline $\begin{array}{l}\text { R-squared } \\
\text { Sum squared resid }\end{array}$ & $\begin{array}{r}-0.107592 \\
2695.855\end{array}$ & $\begin{array}{l}\text { Mean depe } \\
\text { Durbin-Wa }\end{array}$ & $\begin{array}{l}\text { ndent var } \\
\text { tson stat }\end{array}$ & $\begin{array}{l}8.542618 \\
0.245553\end{array}$ \\
\hline
\end{tabular}

(Sumber: Hasil olah data Eviews versi 9.0/2018)

Berdasarkan hasil pengujian analisis regresi data panel secara parsial menunjukan hasil thitung -1.504895 , sementara t-tabel dengan $\alpha=5 \%$ dan df $(n-k)=(100-2)=98$, maka $t-$ tabel $(0,05 ; 98)=1.984$, sehingga t-tabel lebih besar dari t-hitung $(1.984>-1.505)$ jadi $\mathrm{H} 0$ diterima dan Ha ditolak sehingga dapat disimpulkan Debt to Total Asset Ratio (DAR) tidak berpengaruh secara negatif terhadap Net Profit Margin (NPM), kemudian nilai probabilitas 
Debt to Total Asset Ratio (DAR) lebih besar dari konstanta $(0.1356>0,05)$ maka hasil tidak signifikan dari variabel DAR terhadap NPM.

\section{2). Variabel Debt to Equity Ratio (DER)}

$\mathrm{H}_{0}$ 2: Tidak terdapat pengaruh antara Debt to Equity Ratio (DER) terhadap Net Profit Margin (NPM).

$\mathrm{H}_{\mathrm{a}} 2$ : Terdapat pengaruh antara Debt to Equity Ratio (DER) terhadap Net Profit Margin (NPM).

Pengaruh variabel Debt to Equity Ratio (DER) terhadap Net Profit Margin (NPM)

Dependent Variable: NPM

Method: Panel EGLS (Cross-section random effects)

Date: 08/01/18 Time: 23:23

Sample: 20072016

Periods included: 10

Cross-sections included: 10

Total panel (balanced) observations: 100

Swamy and Arora estimator of component variances

\begin{tabular}{|c|c|c|c|c|}
\hline Variable & Coefficient & Std. Error & t-Statistic & Prob. \\
\hline \multirow{4}{*}{$\begin{array}{c}\mathrm{C} \\
\mathrm{DER}\end{array}$} & 12.25744 & 2.356685 & 5.201136 & 0.0000 \\
\hline & -0.351823 & 0.166697 & -2.110558 & 0.0374 \\
\hline & \multirow{2}{*}{\multicolumn{2}{|c|}{ Effects Specification }} & & \\
\hline & & & S.D. & Rho \\
\hline \multicolumn{3}{|c|}{$\begin{array}{l}\text { Cross-section random } \\
\text { Idiosyncratic random }\end{array}$} & 4.921830 & $\begin{array}{l}0.8784 \\
0.1216\end{array}$ \\
\hline
\end{tabular}

\begin{tabular}{lcll}
\hline \hline \multicolumn{4}{l}{ Weighted Statistics } \\
\hline \hline R-squared & 0.043311 & Mean dependent var & 0.998053 \\
Adjusted R-squared & 0.033549 & S.D. dependent var & 1.866188 \\
S.E. of regression & 1.834616 & Sum squared resid & 329.8501 \\
F-statistic & 4.436613 & Durbin-Watson stat & 1.974701 \\
Prob(F-statistic) & 0.037731 & & \\
\hline \hline & Unweighted & Statistics & \\
\hline \hline R-squared & -0.066164 & Mean dependent var & 8.542618 \\
Sum squared resid & 2595.021 & Durbin-Watson stat & 0.251002 \\
\hline
\end{tabular}

(Sumber: Hasil olah data Eviews versi 9.0/2018)

Berdasarkan tabel 4.33 hasil pengujian analisis regresi data panel secara parsial menunjukan hasil t-hitung -2.110558 , sementara t-tabel dengan $\alpha=5 \%$ dan df $(n-2)=(100-2)=98$, maka t-tabel $(0,05 ; 98)=1.984$, sehingga sehingga t-tabel lebih besar dari t-hitung (1.984 > - 2.110) jadi $\mathrm{HO}$ diterima dan $\mathrm{Ha}$ ditolak sehingga dapat disimpulkan Debt to Equity Ratio (DER) tidak berpengaruh secara negatif terhadap Net Profit Margin (NPM), kemudian nilai probabilitas Debt to Equity Ratio (DER) lebih kecil dari konstanta $(0.0374<0,05)$ maka hasilnya signifikan dari variabel DER terhadap NPM.

\section{3). Variabel Net Profit Margin (NPM)}

$\mathrm{H}_{0}$ 4: Tidak terdapat pengaruh antara Net Profit Margin (NPM) terhadap Harga Saham. 
$\mathrm{H}_{\mathrm{a}} 4$ : Terdapat pengaruh antara Net Profit Margin (NPM)terhadap Harga Saham.

Pengaruh variabel Net Profit Margin (NPM) terhadap Harga Saham

Dependent Variable: Harga Saham

Method: Panel EGLS (Cross-section random effects)

Date: 08/01/18 Time: 23:32

Sample: 20072016

Periods included: 10

Cross-sections included: 10

Total panel (balanced) observations: 100

Swamy and Arora estimator of component variances

\begin{tabular}{crrrr}
\hline \hline Variable & Coefficient & Std. Error & t-Statistic & Prob. \\
\hline \hline C & 14.17653 & 0.676596 & 20.95272 & 0.0000 \\
NPM & 0.023635 & 0.048703 & 0.485290 & 0.6286 \\
\hline \hline
\end{tabular}

\begin{tabular}{lcc}
\hline \hline & Effects Specification & \\
& S.D. & Rho \\
\hline \hline Cross-section random & 1.660068 & 0.7518 \\
Idiosyncratic random & 0.953848 & 0.2482 \\
\hline \hline
\end{tabular}

\begin{tabular}{lrll}
\hline \hline \multicolumn{4}{c}{ Weighted Statistics } \\
\hline \hline R-squared & 0.002341 & Mean dependent var & 2.570464 \\
Adjusted R-squared & -0.007840 & S.D. dependent var & 0.961596 \\
S.E. of regression & 0.965358 & Sum squared resid & 91.32769 \\
F-statistic & 0.229924 & Durbin-Watson stat & 0.970567 \\
Prob(F-statistic) & 0.632649 & & \\
\hline \hline & Unweighted Statistics & \\
\hline \hline R-squared & -0.046848 & Mean dependent var & 14.37844 \\
Sum squared resid & 388.4871 & Durbin-Watson stat & 0.228166 \\
\hline \hline
\end{tabular}

(Sumber: Hasil olah data Eviews versi 9.0/2018)

Berdasarkan tabel 4.35 hasil pengujian analisis regresi data panel secara parsial menunjukan hasil t-hitung 0.485290 , sementara t-tabel dengan $\alpha=5 \%$ dan df $(n-k)=(100-2)$ $=98$, maka t-tabel $(0,05 ; 98)=1.984$, sehingga t-tabel lebih besar dari t-hitung $(1.984>$ 0.4852 ) jadi HO ditolak dan Ha diterima sehingga dapat disimpulkan Net Profit Margin (NPM) berpengaruh secara positif terhadap Harga Saham, kemudian nilai probabilitas Net Profit Margin (NPM) lebih besar dari konstanta $(0.628>0,05)$ maka hasil tidak signifikan dari variabel Harga Saham terhadap NPM.

\section{b) Pengujiam Hipotesis Secara Simultan (Uji F)}

Pengujian hipotesis secara simultan ini dilakukan dengan menggunakan Uji $F$ untuk mengetahui apakah semua variabel independent yang digunakan dalam secara serentak atau bersama-sama berpengaruh terhadap variabel dependent, dengan membandingkan $F$ hitung dan $\mathrm{F}$ tabel. 
$\mathrm{H}_{0} 3$ : Tidak terdapat pengaruh antara Debt to Total Asset Ratio

(DAR) dan Debt to Equity Ratio (DER) terhadap Net

Profit Margin (NPM).

$\mathrm{H}_{\mathrm{a}} 3$ : Terdapat pengaruh antara Debt to Total Asset Ratio (DAR)

dan Debt to Equity Ratio (DER) terhadap Net Profit

Margin (NPM).

\section{Pengaruh variabel Debt to Equity Ratio (DER) dan Debt to Equity Ratio (DER)} terhadap Net Profit Margin (NPM)

Dependent Variable: NPM

Method: Panel EGLS (Cross-section random effects)

Date: 08/01/18 Time: 23:27

Sample: 20072016

Periods included: 10

Cross-sections included: 10

Total panel (balanced) observations: 100

Swamy and Arora estimator of component variances

\begin{tabular}{crrrr}
\hline \hline Variable & Coefficient & Std. Error & t-Statistic & Prob. \\
\hline \hline C & 8.162756 & 8.616973 & 0.947288 & 0.3458 \\
DAR & 0.676755 & 1.367137 & 0.495017 & 0.6217 \\
DER & -0.488622 & 0.322389 & -1.515628 & 0.1329 \\
\hline
\end{tabular}

\begin{tabular}{lrc}
\hline \hline & Effects Specification & \\
& S.D. & Rho \\
\hline \hline Cross-section random & 4.986363 & 0.8800 \\
Idiosyncratic random & 1.841288 & 0.1200 \\
\hline \hline
\end{tabular}

Weighted Statistics

\begin{tabular}{llll}
\hline \hline R-squared & 0.045878 & Mean dependent var & 0.990805 \\
Adjusted R-squared & 0.026206 & S.D. dependent var & 1.865055 \\
S.E. of regression & 1.840455 & Sum squared resid & 328.5656 \\
F-statistic & 2.332093 & Durbin-Watson stat & 1.991249 \\
Prob(F-statistic) & 0.102514 & & \\
\hline \hline
\end{tabular}

Unweighted Statistics

\begin{tabular}{lrll}
\hline \hline R-squared & -0.023859 & Mean dependent var & 8.542618 \\
Sum squared resid & 2492.052 & Durbin-Watson stat & 0.262537
\end{tabular}

(Sumber: Hasil olah data Eviews versi 9.0/2018)

Berdasarkan tabel 4.34 hasil pengujian analisis regresi data panel dengan menggukan eviews yang ditunjukan tabel 4.16 diatas, nilai $F$ hitung yang sebesar 2.332093 sementara sementara f-tabel dengan $\alpha=5 \%$, df $1=3-1=2$; df2 $=100-3=97$ di dapat F-tabel 3.09 . dengan demikian F-hitung < F tabel $(2.332093<3.09)$ jadi $\mathrm{HO}$ diterima dan Ha ditolak, sehingga dapat disimpulkan bahwa variabel independen secara bersama-sama tidak memiliki pengaruh terhadap variabel dependen. kemudian nilai probabilitas sebesar 0.102514 yang lebih besar dari tingkat signifikan $0,05(0.102514>0,05)$ sehingga $\mathrm{H} 0$ diterima dan Ha ditolak. Hal ini berarti bahwa variabel Debt to Total Asset Ratio (DAR) dan 
Debt to Equity Ratio (DER) secara bersama-sama atau simultan tidak berpengaruh positif dan tidak signifikan terhadap Net Profit Margin (NPM).

\section{E. SIMPULAN}

\section{Kesimpulan}

Berdasarkan pembahasan dan hasil penelitian mengenai pengaruh Debt to Total Asset Ratio (DAR) dan Debt to Equity Ratio (DER) terhadap Net Profit Margin (NPM) serta dampaknya terhadap Harga Saham pada Perusahaan Elektronik di Bursa Efek Tokyo (TSE) tahun 2007-2016, penelitian ini menggunakan metode data panel menggunakan Eviews 9, dari hasil penelitian dapat disimpulkan beberapa hal sebagai berikut:

1. Tidak Terdapat pengaruh negatif dan tidak signifikan antara Debt to Total Asset Ratio (DAR) terhadap Net Profit Margin (NPM). Hal ini dilihat dari hasil Uji Eviews 9.0 secara parsial menunjukan hasil t-hitung -1.504895 , sementara $t-$ tabel dengan $\alpha=5 \%$ dan df $(n-k)=(100-2)=98$, maka t-tabel $(0,05 ; 98)=1.984$, sehingga t-tabel lebih besar dari t-hitung $(1.984>-1.505)$ jadi $\mathrm{HO}$ diterima dan Ha ditolak, dan probabilitas Debt to Total Asset Ratio (DAR) lebih besar dari konstanta $(0.1356>0,05)$ maka hasil tidak signifikan dari variabel DAR terhadap NPM.

2. Tidak Terdapat pengaruh negatif dan signifikan antara Debt to Equity Ratio (DER) terhadap Net Profit Margin (NPM). Hal ini dilihat dari hasil Uji Eviews 9.0 secara parsial menunjukan hasil t-hitung -2.110558 , sementara t-tabel dengan a $=5 \%$ dan df $(n-2)=(100-2)=98$, maka t-tabel $(0,05 ; 98)=1.984$, sehingga sehingga t-tabel lebih besar dari t-hitung (1.984 > - 2.110) jadi H0 diterima dan Ha ditolak, dan nilai probabilitas Debt to Equity Ratio (DER) lebih besar dari konstanta $(0.0374<0,05)$ maka hasilnya signifikan dari variabel DER terhadap NPM

3. Debt to Total Asset Ratio (DAR) dan Debt to Equity Ratio (DER) terhadap Net Profit Margin (NPM) secara simultan atau bersama-sama tidak terdapat pengaruh positif dan tidak signifikan terhadap Net Profit Margin (NPM), dimana nilai $F$ hitung sebesar 2.332093 sementara f-tabel dengan $\alpha=5 \%$, df $1=3-1=2$; df2 $=100-3=97$ di dapat F-tabel 3.09. dengan demikian F-hitung $<F$ tabel $(2.332093<3.09)$ jadi HO diterima dan Ha ditolak dan nilai probabilitas sebesar 0.102514 yang lebih besar dari tingkat signifikan $0,05(0.102514>0,05)$ sehingga $\mathrm{HO}$ diterima dan Ha ditolak.

4. Net Profit Margin (NPM) terdapat pengaruh positif dan tidak signifikan terhadap Harga Saham. Hal ini dilihat dari hasil Uji Eviews 9.0 secara parsial menunjukan hasil t-hitung 0.485290 , sementara t-tabel dengan $\alpha=5 \%$ dan $\mathrm{df}(\mathrm{n}-\mathrm{k})=(100-2)=$ 98 , maka t-tabel $(0,05 ; 98)=1.984$, sehingga t-tabel lebih besar dari t-hitung (1.984 > 0.4852) jadi $\mathrm{HO}$ ditolak dan Ha diterima sedangkan nilai probabilitas Net Profit Margin (NPM) lebih besar dari konstanta $(0.628>0,05)$ maka hasil tidak signifikan dari variabel Harga Saham terhadap NPM.

\section{Saran}

a) Bagi Penulis penelitian ini dapat membuka wawasan baru. Bahwa faktor ekonomi makro juga dapat berpotensi mempengaruhi kinerja bursa saham, jadi tidak hanya faktor-faktor internal bursa itu sendiri saja. Penelitian ini hanya melihat pengaruh Debt to Total Asset Ratio (DAR) dan Debt to Equity Ratio (DER) terhadap Net Profit Margin (NPM) terhadap Harga Saham untuk beberapa periode waktu pengamatan yaitu dari tahun 2007 sampai dengan tahun 2016, hal ini dapat diketahui dari nilai Adjusted $R$ Square yang tidak mencapai $100 \%$ yang mengindikasikan bahwa masih banyak varaibel 
independen lain yang dapat digunakan untuk mengetahui pengaruhnya terhadap Harga Saham.

b) Bagi Perusahaan sebaiknya memperlihatkan langsung pos-pos yang mempengaruhi harga saham pada laporan keuangannya agar masyarakat yang awam akan lebih mengetahui baik atau tidaknya perusahaan tersebut dengan tujuan agar tidak salah dalam mengambil keputusan ketika akan berinvestasi. Pada penelitian ini secara simultan hanya Debt to Total Asset Ratio (DAR) dan Debt to Equity Ratio (DER) yang mempunyai pengaruh negatif terhadap Net Profit Margin (NPM). Hal ini menunjukkan bahwa perusahaan perlu memperhatikan faktor tersebut sehingga dapat menarik pihak investor untuk menanamkan modalnya sehingga meningkatkan permintaan Harga Saham.

c) Bagi Investor dalam menanam modal hendaknya investor tidak hanya memperhatikan saja terhadap kinerja keuangan, naum juga factor-faktor di luar kinerja keuangan. faktor-faktor lain tersebut misalnya bias lingkungan social, ekonomi, politik serta kebijakan pemerintah. Berkenaan dengan indikatorindikator tersebut maka investor perlu juga mempertimbangkan investasi jangka panjang dan jangka pendek dalam berinvestasi dan sebaiknya memperhatikan tingkat nilai harga saham perusahaan untuk melakukan pertimbangan dalam melakukan investasi dengan menganalisis terlebih dahulu kondisi perusahaan melalui Net Profit Margin (NPM), karena dalam penelitian ini rasio tersebut yang mempunyai pengaruh positif terhadap Harga Saham.

d) Bagi Peneliti Selanjutnya apabila akan dilakukan penelitian sejenis yang lebih lanjut sebaiknya peneliti menambah jumlah sampel penelitian, menambah periode pengamatan dan objek penelitian lainnya pada perusahaan sejenis yang lebih banyak, agar labih fokus dan juga pengembangan variabel lain agar diperoleh hasil yang lebih baik, sehingga bisa meneliti pengaruh nilai rasio keuangan terhadap harga saham dengan tingkat akurasi yang lebih tinggi. Selain itu juga bisa dengan menambahkan variabel lain yang belum diteliti agar dapat membentuk model penelitian yang lebih baik lagi dan perlu Penelitian lebih lanjut mengenai Debt to Total Asset Ratio (DAR) dan Debt to Equity Ratio (DER) terhadap Net Profit Margin (NPM) terhadap Harga Saham. 


\section{DAFTAR PUSTAKA}

Abdul Sani, Ridwan. 2013. Inovasi Pembelajaran. Bumi Aksara: Jakarta

Agnes, Sawir. 2008. Analisis Kinerja Keuangan dan Perencanaan Keuangan. Jakarta: Pt Gramedia Pustaka Utama.

Agus Sartono. 2008, “Manajemen Keuangan Teori Dan Aplikasi”, Edisi 4, Penerbit : BPFE, Yogyakarta.

Anoraga, Pandji. 2000. Manajemen Bisnis. Jakarta: Rineka Cipta

Bambang Riyanto. 2004. Dasar-Dasar Pembelanjaan Perusahaan. Yogyakarta : BPFC. Edisi ke 4.

Basrowi \& Suwandi. (2010). Memahami Penelitian Kualitatif. Jakarta: Rineka Cipta

Birgham, F. Eugene \& Joel F. Houston. 2010, “Dasar-dasar Manajemen Keuangan”. Edisi II \& Buku 1, Penerbit : Salemba Empat, Jakarta.

Boediono, "Ekonomi Indonesia, Mau Kemana?. Kumpulan Essai Ekonomi, Kepustakaan Populer", Gramedia, 2009.

Darsono. 2009, “Manajemen Keuangan”, Penerbit : Nusantara Consulting, Jakarta.

Edduar Hendri. 2015. "Pengaruh Debt To Asset Ratio (DAR), Long Term Debt To Equity Ratio (LTDER) Dan Net Profit Margin (NPM) Terhadap Harga Saham Pada Perusahan Perbankan Yang Terdaftar Di Bursa Efek Indonesia" (Journal of UPGRI Palembang)"

Gerald Edsel Yermia Egam, Ventje Ilat, Sonny Pangerapan. 2017. "The Influences Of Return On Asset (ROA), Return On Equity (ROE), Net Profit Margin (NPM), And Earning Per Share (EPS) Against The Stock Prices Of The Companies Listed On Lq45 Index In Indonesian Stock Exchange On The Period Of 2013-2015" (Journal of Fakultas Ekonomi dan Bisnis Universitas Sam Ratulangi Manado)

Griffin, Ricky W. 2004. Manajemen. Edisi Kesepuluh. Jakarta: Erlangga.

Gujarati, N Damodar. 2004, “Basic Econometrics Fourth Edition”, Mc. Grawhill.

Hanafi, Mamduh M dan Abdul Halim, 2002, Analisis Laporan Keuangan, Edisi Kedua, Yogyakarta : STIE YKPN.

Harahap, Sofyan Syafri. 2013. Analisis Kritis Atas Laporan Keuangan Edisi 11. Rajawali Pers, Jakarta.Syamsuddin (2006:30)

Horne, james C. Van dan John M Wachowicz, Jr. 2012. Prinsip-prinsip Manajemen Keuangan (Edisi 13). Jakarta : Salemba Empat

Ikatan Akuntan Indonesia, 2004. Standar Akuntansi Keuangan. PSAK No. 17, Penerbit Salemba Empat, Jakarta.

Jogiyanto, "Teori Portofolio dan Analisis Investasi", edisi kedua, Penerbit BPPE. Yogyakarta, 2008. 
Kasmir. 2014. Analisis Laporan Keuangan. Edisi Satu. Cetakan Ketujuh. Jakarta : PT Raja Grafindo Persada.

Kerlinger, Fred N, 2006. Asas-Asas Penelitian Behavioral. Penerbit Universitas Gadjah Mada. Yogyakarta.

Lutfi, A. M., \& Sunardi, N. (2019). Pengaruh Current Ratio (Cr), Return On Equity (Roe), Dan Sales Growth Terhadap Harga Saham Yang Berdampak Pada Kinerja Keuangan Perusahaan (Pada Perusahaan Manufaktur Sektor Makanan Dan Minuman Yang Terdaftar Di Bursa Efek Indonesia). Jurnal SEKURITAS (Saham, Ekonomi, Keuangan dan Investasi), 2(3), 83-100.

Manullang M, 2006, Dasar-Dasar Manajemen, edisi revisi, cetakan ketujuh, Penerbit : Ghalia Indonesia, Jakarta

Manullang M, 2012. Dasar-dasar Manajemen Bagi Pimpinan Perusahaan. Jakarta. Gajah Mada Press.

Munawir S, 2010. Analisa Laporan Keuangan. Yogyakarta: Liberty

Murni, Asfia, “Ekonomi Makro”, PT Refika Aditama, Jakarta 2006.

Nasaruddin, M.Irsan dan Indra Surya. 2004. "Aspek Hukum Pasar Modal Indonesia", Jakarta: Prenada Media.

Neneng Tita Amalya, 2018, "Pengaruh ROA, ROE, NPM, Dan DER Terhadap Harga Saham (Studi Kasus Pada Perusahaan Pertambangan Sub Sektor Batu Bara Yang Terdaftar di Bursa Efek Indonesia)"

Oliver Ike Inyiama. 2014. "Working Capital Ratio and Earnings Per Share. Do They Interact? Evidence from Nigeria Brewery Industry" (The International Journal Of Business \& Management Enugu State University of Science and Technology, Nigeria)

Reni Wuryaningrum. 2015. "Pengaruh Rasio Keuangan Terhadap Harga Saham Pada Perusahaan Farmasi Di BEP'. (Jurnal IImu dan Riset Manajemen Volume 4, Nomor 11, Sekolah Tinggi Ilmu Ekonomi Indonesia (STIESIA) Surabaya).

Riduwan. 2010. Belajar Mudah Penelitian untuk Guru Dan Karyawan dan Peneliti Pemula. Bandung: Alfabeta

Riyanto, Bambang. 2008. Dasar-dasar Pembelanjaan Perusahaan. Yogyakarta: Penerbit GPFE

Samuelson, Paul A and Nordhaus, William D, "Macro Economics $14^{\text {th }}$ and $17^{\text {th }}$ edition", Published by Mc Grau Hill Companies New York, Copy right 2001.

Sawidji Widoatmodjo, Cara Sehat Investasi di Pasar Modal : Pengetahuan Dasar, Jakarta : Yayasan Mpu Ajar Artha, 2000).

Siegel, G. Joel dan Jae K. Shim, 2012 Budgeting, Erlangga, Jakarta

Sugiyono. 2010, "Metode Penelitian Kuantitatif Kualitatif dan RnD”, Penerbit : Afabeta, Bandung.

Sugiyono. 2011. Metode Penelitian Kuantitatif, Kualitatif dan R\&D. Bandung: Afabeta. 
Sugiyono. 2014. Metode Penelitian Pendidikan Pendekatan Kuantitatif, Kualitatif Dan R\&D. Bandung: Alfabeta.

Sunardi, N. (2019). Profitabilitas, Likuiditas, Dan Multiplier Equity Pengaruhnya Terhadap Harga Serta Return Saham Pada Industri Manufaktur Tahun 20122017. INOVASI, 6(1), 58-73.

Sunardi, N., \& Permana, R. D. I. (2019). Faktor-Faktor Yang Mempengaruhi Harga Saham Dan Dampaknya Pada Nilai Perusahaan (Studi Kasus pada Perusahaan Sub Sektor Pertambangan Minyak dan Gas Bumi yang Terdaftar di Bursa Efek Indonesia Tahun 2013-2017). JIMF (Jurnal IImiah Manajemen Forkamma), 2(1).

Sunardi, N., \& Ula, L. N. R. (2017). Pengaruh BI Rate, Inflasi Dan Kurs Terhadap Indeks Harga Saham Gabungan (IHSG). Jurnal Sekuritas: Saham, Ekonomi, Keuangan dan Investasi, 1(2), 27-41.

Tomi Sanjaya, Dwiatmanto, Maria Goretti Wi Endang NP, 2015, "Pengaruh Return,On Equity (ROE), Debt To Asset Ratio (DAR), Debt To Equity Ratio (DER), Earning,Per Share (EPS) Terhadap Harga Saham (Studi pada perusahaan Food and Beverage yang,terdaftar di,Bursa Efek,Indonesia Periode 2011-2013)"

Veithzal Rivai. (2007). Bank and Financial Institute Management. Jakarta: PT. Raja Grafindo Persada.

Warner R Murhadi. 2013. Analisis Laporan Keuangan, Proyeksi dan Valuasi Saham. Jakarta. Salemba Empat.

Weston, J. Feed dan Thomas E. Copeland. 2009. Manajemen Keuangan. Jakarta: Binarupa Aksara.

Zaenal, Junggi Markus, 2014, "Pengaruh Current Ratio dan Debt to Equity Ratio terhadap Harga Saham (Studi Empiris pada perusahaan sub Sektor Pertambangan Batu Bara yang terdaftar pada BEI)" 